\title{
Intestinal carriage of Staphylococcus aureus: how does its frequency compare with that of nasal carriage and what is its clinical impact?
}

\author{
D. S. Acton • M. J. Tempelmans Plat-Sinnige • \\ W. van Wamel • N. de Groot • A. van Belkum
}

Received: 16 June 2008 / Accepted: 11 July 2008 / Published online: 8 August 2008

(C) The Author(s) 2008

\begin{abstract}
The bacterial species Staphylococcus aureus, including its methicillin-resistant variant (MRSA), finds its primary ecological niche in the human nose, but is also able to colonize the intestines and the perineal region. Intestinal carriage has not been widely investigated despite its potential clinical impact. This review summarizes literature on the topic and sketches the current state of affairs from a microbiological and infectious diseases' perspective. Major findings are that the average reported detection rate of intestinal carriage in healthy individuals and patients is $20 \%$ for S. aureus and $9 \%$ for MRSA, which is approximately half of that for nasal carriage. Nasal carriage seems to predispose to intestinal carriage, but sole intestinal carriage occurs relatively frequently and is observed in 1 out of 3 intestinal carriers, which provides a rationale to include intestinal screening for surveillance or in outbreak settings. Colonization of the intestinal tract with $S$. aureus at a young age occurs at a high frequency and may affect the host's immune system. The frequency of intestinal carriage is generally underestimated and may significantly contribute to bacterial dissemination and subsequent risk of infections. Whether intestinal rather than nasal $S$. aureus carriage is a primary predictor for infections is still ill-defined.
\end{abstract}

\footnotetext{
D. S. Acton $(\varangle) \cdot$ M. J. Tempelmans Plat-Sinnige $\cdot$ N. de Groot Mucovax B.V.,

Niels Bohrweg 11-13,

2333 CA Leiden, The Netherlands

e-mail: dacton@mucovax.nl
}

M. J. Tempelmans Plat-Sinnige $\cdot$ W. van Wamel $\cdot$ A. van Belkum Department of Medical Microbiology

and Infectious Diseases, Erasmus MC,

Gravendijkwal 230,

3015 CE Rotterdam, The Netherlands

\section{Introduction}

Nasal colonization by Staphylococcus aureus is a wellestablished risk factor for acute cutaneous infections, postoperative infections, as well as most other types of $S$. aureus infections [1-3]. Several recent studies have suggested that lasting colonization of $S$. aureus in the human intestinal tract also occurs and that this may have important clinical implications. Still, compared to nasal carriage, gastro-intestinal colonization by $S$. aureus has been sparsely studied.

In the 1950s and 1960s, intestinal S. aureus carriage was first defined and studied as a potential cause of antibioticassociated diarrhea (AAD) [4]. However, after the identification of Clostridium difficile as the most common pathogen of hospital-acquired AAD in the 1970s [5], the role of gastro-intestinal colonization as a risk factor for (intestinal) $S$. aureus infection has been neglected for decades and the issue has only recently re-emerged. The pandemic rise in the incidence of methicillin-resistant $S$. aureus (MRSA) strains, as opposed to methicillin-sensitive $S$. aureus (MSSA), has contributed greatly to the renewed interest in intestinal $S$. aureus colonization. This covered investigations into risk factors for both AAD as well as health care-associated (HA) infections. Furthermore, community-acquired (CA) MRSA infection among individuals without "HA risk factors" was first recognized in the late 1990s. CA-MRSA is now emerging as an apparent epidemic. In recent studies, in addition to nasal carriage, rectal carriage of CA-MRSA has also been documented. In this review we will give an historical update and a systemic overview of the more recent studies related to intestinal and/or perineal carriage of $S$. aureus (MSSA, HA-MRSA, and CA-MRSA) and we will discuss its clinical implications. 


\section{Culture methods and definition of perineal and intestinal carriage}

Techniques to determine carriage or colonization can be based on classical culture assays using selective broths or agars for MSSA, as well as novel growth-based phenotypic and molecular methods for both MSSA and MRSA detection [6]. Methods used to define intestinal carriage include culture of stool, rectal swabs or anal swabs. Also, swabs from the perianal area (including the perineum and the groin or inguinal region) are generally accepted to define intestinal carriage. For these sites, however, it can be argued that these may also represent skin carriage. In a limited number of reports direct comparison of the frequency yields for these different sites of colonization within the same study have been presented. Rectal swabs were reported to have higher yields of $S$. aureus detection than stool cultures [7], but a more recent comparison [8] gave opposite results for MRSA. Other studies reported similar frequencies of carriage for both perianal and groin sites of carriage for nursing home residents and hospitalized patients respectively $[9,10]$. Also, direct comparisons of the rectal and perineal sites gave similar frequencies of detection [11] and in another recent study screening of the perineal area, the rectum and the inguinal area gave similar frequencies of detection of MRSA [12], which legitimates the use of all of these sites to define intestinal carriage.

\section{Intestinal carriage frequencies of $S$. aureus in adults}

Most early studies on the intestinal carriage of $S$. aureus were performed on hospitalized patients and timely overviews of frequencies of intestinal carriage in adults upon admission to the hospital were reported [4, 13]. The frequencies found in these relatively ancient studies ranged from 8 to $31 \%$ (Table 1). Among adults, nasal $S$. aureus carriers were reported to yield $S$. aureus from their feces more often than non-nasal carriers did. Strain typing suggested involvement of the same strains for both colonization sites [14]. Vice versa, about $50-70 \%$ of perineal carriers were also nasal carriers of the same strain [15]. It was reported that of 50 healthy male students screened, $11(22 \%)$ had perineal carriage of $S$. aureus and that 5 of these were non-nasal carriers $(10 \%)$ [16]. This implied that non-nasal carriers might be susceptible to intestinal carriage, suggesting that mechanisms for nasal and intestinal carriage differ.

More recent data on the intestinal carriage of S. aureus in adults were generated as part of studies mostly aimed at identifying MRSA. In most of these studies the patients were screened for intestinal as well as nasal carriage, allowing a comparison of these sites of colonization
Table 1 Reported frequencies of intestinal carriage of $S$. aureus in adults upon admission to hospital in early studies

\begin{tabular}{lc}
\hline Reference & Percentage positives \\
\hline$[92]$ & 18 \\
{$[93]$} & 17 \\
{$[14]$} & 23 \\
{$[94]$} & 31 \\
{$[95]$} & 8 \\
{$[16]$} & 22 \\
{$[96]$} & 21 \\
{$[15]$} & 12 \\
{$[97]$} & 13 \\
\hline
\end{tabular}

(Table 2). For instance, in a study on 500 pregnant women attending an antenatal clinic a frequency of intestinal carriage of $S$. aureus of $12 \%$ (59 patients) and a nasal carriage frequency of $24 \%$ (120 patients) were reported [17]. Interestingly, $8 \%$ (41) of the patients had intestinal carriage in the absence of nasal carriage, covering $25 \%$ of all $S$. aureus-positive patients. Among patients in a skilled nursing facility, nasal and rectal swabs or stools were surveyed for MSSA and MRSA. Of these, 22\% (76 patients) had intestinal carriage of $S$. aureus [18]. Ten percent of the patients $(n=34)$ were intestinal carriers in the absence of nasal carriage.

The prevalence of $S$. aureus colonization of the perineum was examined in a longitudinal study on 84 communitydwelling adults with spinal cord dysfunction [19]. S. aureus was detected in 20 (24\%) individuals. Nasal carriage was detected in $55 \%$ of all patients from a subset of 22 patients of whom $23 \%$ had intestinal carriage only. By follow-up of 30 patients with at least five cultures for 1 year, the perineal carriage pattern was assessed. They found that $10 \%$ had persistent carriage, $63 \%$ had intermittent carriage, and $27 \%$ were non-carriers, in agreement with nasal carriage patterns [1]. Paired perineal/nasal carriage was determined for 22 participants. Of the 16 perineal carriers in this group, $5 \mathrm{did}$ not have nasal carriage. Among the 11 with both perineal and nasal carriage, all but 1 carried the same spa type at both sites. Many similar studies were performed, the results of which are summarized in Table 2.

Altogether the frequency of nasal carriage detection of $S$. aureus ranged from $24 \%$ to $61 \%$ and intestinal carriage frequencies in these studies ranged from $10 \%$ to $37 \%$. These ranges probably reflect the different criteria used for the selection of patient groups and the differences in risk of $S$. aureus colonization or infection amongst these heterogeneous groups of patients from different geographical regions. Therefore, calculation of an overall frequency of $S$. aureus carriage from these studies by using actual total numbers of patients may be debated, but, nevertheless, results in approximately $20 \%$ of cases of intestinal carriage 
Table 2 Frequencies of detection of $S$. aureus (including MRSA) with regard to intestinal and nasal carriage and intestinal carriage in the absence of nasal carriage in adults

\begin{tabular}{|c|c|c|c|c|c|c|c|}
\hline Reference & $\begin{array}{l}\text { Total } \\
\text { number of } \\
\text { patients } \\
\text { screened }\end{array}$ & $\begin{array}{l}\text { Intestinal carriage, } \\
\text { percentage of } \\
\text { total }(n) \text { or } \\
(n / \text { total })\end{array}$ & $\begin{array}{l}\text { Nasal carriage, } \\
\text { percentage of } \\
\text { total }(n) \text { or } \\
\left(n / \text { total }^{\mathrm{a}}\right)\end{array}$ & $\begin{array}{l}\text { Intestinal carriage } \\
\text { in the absence } \\
\text { of nasal carriage, } \\
\text { percentage of total } \\
\left(n / \text { total }^{\mathrm{a}}\right)\end{array}$ & $\begin{array}{l}\text { Intestinal carriage } \\
\text { in the absence of } \\
\text { nasal carriage, } \\
\text { percentage of } \\
\text { intestinal carriers } \\
\left(n / \text { total }^{\mathrm{a}}\right)\end{array}$ & Method used & Patient group \\
\hline [17] & 500 & $12(59)$ & $24(120)$ & $8(41)$ & 70 & Perineal swabs & Pregnant women \\
\hline [77] & 37 & $24(9)$ & $30(15 / 50)$ & NS & NS & Rectal swab & $\begin{array}{c}\text { Mothers } 1 \text { week after } \\
\text { delivery }\end{array}$ \\
\hline [55] & 62 & $11(7)$ & $44(27)$ & $3(2)$ & 29 & Perineal swabs & Healthy adults \\
\hline [18] & 354 & $22(76)$ & $61(214)$ & $10(34)$ & 45 & Stools & Private SNF patients \\
\hline [48] & 204 & $29(59)$ & $47(96)$ & $3(7)$ & 12 & Rectal swabs & ICU liver transplant patients \\
\hline [24] & 231 & $10(24)$ & $30(70)$ & $5(11)$ & 46 & Perineal swabs & Intensive care patients \\
\hline [90] & 94 & $37(35)$ & $49(47 / 96)$ & $10(9)$ & 26 & Rectal swabs & Liver transplant recipients \\
\hline [44] & 71 & $37(26)$ & $51(36)$ & $4(3)$ & 12 & Stools & Selected inpatients \\
\hline$[10]$ & 213 & $25(54)$ & $43(91)$ & NS & NS & Perianal swabs & Nursing home residents \\
\hline Totals & 1,766 & $20(349 / 1,766)$ & $40(716 / 1,781)$ & $8(112 / 1,538)$ & $37(112 / 302)$ & & \\
\hline
\end{tabular}

NS, not specified; SNF, skilled nursing facilities; ICU, intensive care unit

${ }^{a}$ Totals are indicated when frequencies are based on a different total number of patients screened

compared with nasal carriage of approximately $40 \%$. When reported frequencies of the separate studies are plotted, it appears as if there is a linear correlation between the incidence of nasal and intestinal carriage (see Fig. 1). The slope of the linear regression is 0.55 , which suggests that intestinal carriage is probably preceded by nasal carriage. However, sole intestinal carriage also seems to occur with frequencies ranging from $3-10 \%$. When intestinal carriage in the absence of nasal carriage is calculated from these studies using actual numbers of patients a figure of $8 \%$ is obtained. Furthermore, on average, 1 out of 3 intestinal carriers (37\%) does not seem to be colonized in the nares (Table 2).

Obviously, compared with nasal carriage the intestinal carriage of $S$. aureus is less frequent, but still may have important clinical consequences.

\section{Intestinal MRSA in adult patients at high risk}

During the last 2 decades, a number of studies have reported intestinal screening to determine carriage of MRSA beyond the nasal cavity, in patients at high risk of MRSA at admission or during a stay in a hospital (Table 3). Long-term care patients were analyzed and detection of MRSA was reported in stools from 29 out of 354 patients (8\%) [18]. Nasal carriage frequency was $15 \%$ (52 patients). The detection of 2 MRSA patients on the basis of 10 stool cultures (20\%), obtained during an outbreak in an institution for adults with developmental disabilities, was reported, whereas nasal screening detected MRSA in 16 out of 28 patients $(57 \%)$ [20]. A frequency of intestinal carriage of $10 \%$ (8 out of 84 ) in community-dwelling patients with spinal cord dysfunction was recorded [19]. Nasal screening of a subgroup of 22 of these patients revealed a nasal MRSA frequency of 55\% (12 patients). Furthermore, 205 patients were analyzed who were known to be previously colonized and/or infected with MRSA. Intestinal carriage detection frequency was 33\% and nasal carriage detection frequency was $52 \%$ [21]. Many other reports describing similar data are surveyed in Table 3. When totals are calculated from these reports, the average nasal carriage frequency in these patients at high risk was $12 \%$ and intestinal carriage frequency was $9 \%$.

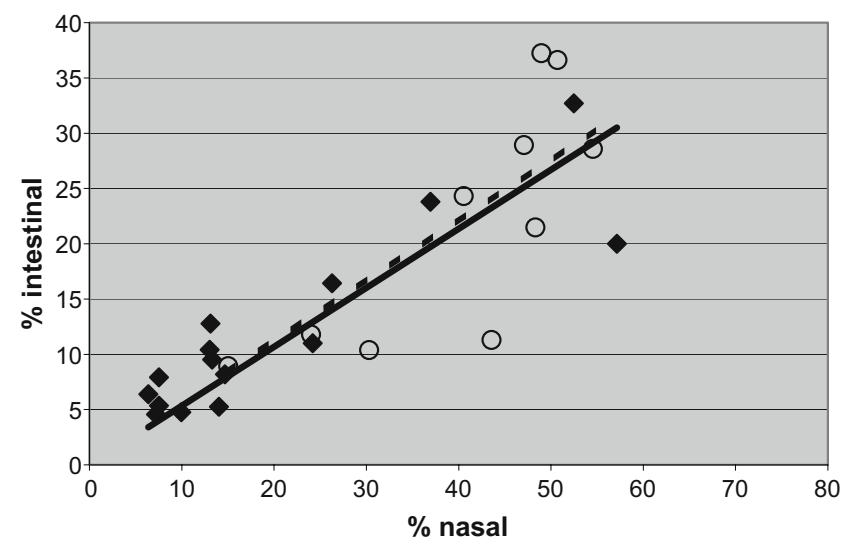

Fig. 1 Relation between frequencies of nasal and intestinal carriage for $S$. aureus (circles) and for MRSA (diamonds). Lines show the linear regression of $S$. aureus (dotted line) and MRSA (straight line), the slope of the linear regression lines are 0.55 and 0.53 , and $R^{2}$ are 0.6012 and 0.7381 for $S$. aureus and MRSA respectively. The plotted data for $S$. aureus are extracted from: $[3,10,17-19,24,44,48,77$, 90] and for MRSA from: [10, 18-21, 23, 24, 27, 31, 33, 36, 38, 39, $51,91]$ 
Table 3 The MRSA intestinal carriage and nasal carriage detection frequencies in hospitalized adult patients at high risk

\begin{tabular}{lcclc}
\hline Reference & Total patients screened & Intestinal MRSA, percentage of total $(n)$ & Nasal MRSA percentage of total $\left(n /\right.$ total $\left.{ }^{\mathrm{a}}\right)$ & Method used \\
\hline$[18]$ & 354 & $8(29)$ & $15(52)$ & Stools \\
{$[38]$} & 114 & $5(6)$ & $14(16)$ & Rectal swabs \\
{$[51]$} & 327 & $11(36)$ & $24(117 / 484)$ & Stools \\
{$[20]$} & 10 & $20(2)$ & $57(16 / 28)$ & Perineal swabs \\
{$[33]$} & 411 & $5(22)$ & $7(31)$ & Perineal swabs \\
{$[91]$} & 105 & $10(10)$ & $13(34 / 256)$ & Perineal swabs \\
{$[24]$} & 231 & $5(11)$ & $10(23)$ & $7(90)$ \\
{$[27]$} & 1,250 & $5(57)$ & $13(25)$ & Perineal swabs \\
{$[23]$} & 192 & $10(20)$ & $13(155)$ & Groin swabs \\
{$[31]$} & 1,181 & $13(151)$ & $6(54)$ & Groin swabs \\
{$[39]$} & 845 & $6(54)$ & $37(17 / 46)$ & Rectal swabs \\
{$[19]$} & 84 & $24(20)$ & $52(53 / 101)$ & Perineal swabs \\
{$[21]$} & 52 & $33(17)$ & $8(57)$ & Groin swabs \\
{$[36]$} & 758 & $8(60)$ & $26(56)$ & Perineal swabs \\
{$[10]$} & 213 & $16(35)$ & $12(796 / 6,464)$ & Perineal swabs \\
Totals & 6,127 & $9(530 / 6,127)$ & \\
\hline
\end{tabular}

${ }^{\mathrm{a}}$ Totals are indicated when frequencies are based on different numbers of total patients screened.

Interestingly, when frequencies of nasal and intestinal MRSA carriage are plotted and compared with those reported for S. aureus (Fig. 1) it seems that the incidence of carriage of MRSA is lower than that for $S$. aureus for both the nares and the intestines, which makes sense, since MRSA has been emerging and disseminating as a colonizing bacterium much more recently than $S$. aureus has. However, the slope of the regression of 0.53 for MRSA is the same as that determined for $S$. aureus (0.55), which indicates a similar relation between both sites of carriage for MRSA and suggests that antibiotic resistance does not influence the relative colonization ability for these two sites.

\section{Distribution of MRSA detection sites}

Direct comparison of the distribution of intestinal carriers versus nasal carriers amongst MRSA-colonized patient groups could be deduced from 22 reports (Table 4) [9, 10, $13,18,19,22-29,31-39]$. Table 4 surveys the frequency of patients with intestinal carriage and nasal carriage expressed as a percentage of all MRSA-colonized patients found in the various studies. In general, patients were considered colonized when at least two consecutive cultures from any place in the body grew MRSA, but also single colonization criteria were applied. The frequencies reported ranged from 5 to $76 \%$ and from 34 to $84 \%$ for intestinal and nasal carriage respectively. When the distribution of intestinal and nasal carriage in MRSA-colonized patients is calculated from all of these studies comprising more than 2,000 MRSA-colonized/infected patients, an overall contribution of $45 \%$ is found for intestinal carriage and $58 \%$ for nasal carriage for all MRSA-colonized patients.
In Table 4 the reported frequencies of intestinal MRSA carriage in the absence of nasal carriage are also summarized. For instance, in a study of an MRSA outbreak involving a total of 975 MRSA patients, perineal screening identified an additional $15 \%$ of culture-positive individuals compared with nasal screening only [25]. In this study, the intestines were reported to be the only positive site out of five culture sites in $10 \%$ of the cases. Klotz and coworkers reported that in addition to a high frequency of $24 \%$ MRSA-positive stool cultures, $13 \%$ of the MRSA strains were first observed in the stool before detecting MRSA in other material from these patients [30]. Similarly, in a large Canadian surveillance study [40], comprising more than 10,000 adult patients, the perineal area was found to be the initial site of MRSA colonization or infection in $41 \%$ of the cases. In patients older than 65 years of age, the perineum or rectum was the only positive site in $13 \%$, indicating that nasal screening alone would be sub-optimal in elderly patients. More recently, Zhang et al. [39] reported that nasal screening alone would have detected $76 \%$ of MRSA carriers and that the inclusion of rectal screening increased the detection sensitivity to $96 \%$, indicating $20 \%$ rectal carriers without nasal carriage. Reyes et al. [36] reported an intestinal carriage frequency without nasal carriage in $27 \%$ of their MRSA-positive patients, whereas Mody et al. [10] showed that $23 \%$ of their MRSA carriers were only colonized in the perianal area. Altogether, comparisons of rates of nasal and intestinal carriage of MRSA were recorded in 16 of the studies mentioned (Table 4). It can be calculated from these studies that of all MRSA colonized patients, $58 \%$ were colonized in the nares, whereas $45 \%$ were colonized in the intestines. Of the individuals with gastro-intestinal MRSA, 1 out of $3(35 \%)$ did not carry 
Table 4 Distribution of intestinal and nasal carriage in all MRSA-colonized patients detected in the studies

\begin{tabular}{|c|c|c|c|c|c|c|c|}
\hline References & $\begin{array}{l}\text { Total } \\
\text { MRSA } \\
\text { cases }\end{array}$ & $\begin{array}{l}\text { Intestinal MRSA, } \\
\text { percentage of } \\
\text { total }(n)\end{array}$ & $\begin{array}{l}\text { Nasal MRSA, } \\
\text { percentage of } \\
\text { total }\left(n / \text { total }^{\mathrm{a}}\right)\end{array}$ & $\begin{array}{l}\text { Intestinal without } \\
\text { nasal, percentage } \\
\text { of total }(n)\end{array}$ & $\begin{array}{l}\text { Intestinal without } \\
\text { nasal, percentage } \\
\text { of intestinal carriers }\end{array}$ & Method used & Patient group \\
\hline [22] & 63 & $5(3)$ & $34(24 / 79)$ & Not specified & Not specified & Perineal swabs & $\begin{array}{l}\text { General hospital patients, } \\
\text { MRSA outbreak }\end{array}$ \\
\hline [13] & 117 & $61(70)$ & $53(62)$ & Not specified & Not specified & Rectal swabs & $\begin{array}{l}\text { General hospital patients, } \\
\text { MRSA outbreak }\end{array}$ \\
\hline [26] & 11 & $18(2)$ & $55(6)$ & $0(0)$ & 0 & Anal swabs & SCI patients \\
\hline [32] & 67 & $25(17)$ & $58(37)$ & Not specified & Not specified & Perineal swabs & SCI patients \\
\hline [25] & 723 & $40(289)$ & $47(369 / 789)$ & $15(145)$ & 50 & Perineal swabs & Hospital MRSA outbreak \\
\hline [18] & 62 & $47(29)$ & $84(52)$ & $16(10)$ & 35 & Stools & $\begin{array}{l}\text { Private skilled nursing } \\
\text { facility patients }\end{array}$ \\
\hline [35] & 23 & $17(4)$ & $65(15)$ & $9(2)$ & 50 & Perineal swabs & Acute care patients \\
\hline [34] & 19 & $42(8)$ & $68(13)$ & $5(1)$ & 13 & Perineal swabs & $\begin{array}{l}\text { Acute rehabilitation unit } \\
\text { SCI patients }\end{array}$ \\
\hline$[38]$ & 24 & $25(6)$ & $67(16)$ & $8(2)$ & 33 & Rectal swabs & Skilled care unit patients \\
\hline [33] & 51 & $54(22)$ & $61(31)$ & $18(9)$ & 41 & Perianal swabs & Acute rehabilitation unit \\
\hline [37] & 36 & $50(18)$ & $75(27)$ & $25(9)$ & 50 & Groin swabs & $\begin{array}{l}\text { General hospital, at risk } \\
\text { patients }\end{array}$ \\
\hline [28] & 203 & $26(52)$ & $44(89)$ & Not specified & Not specified & Perineal swabs & Neurosurgery unit patients \\
\hline [29] & 35 & $20(7)$ & $75(21)$ & Not specified & Not specified & Perineal swabs & $\begin{array}{l}\text { General hospital, at risk } \\
\text { patients }\end{array}$ \\
\hline [24] & 30 & $37(11)$ & $77(23)$ & $17(5)$ & 46 & Perineal swabs & ICU patients \\
\hline [9] & 96 & $49(47)$ & $72(72)$ & Not specified & Not specified & Perineal swabs & $\begin{array}{l}\text { University hospital, at risk } \\
\text { patients }\end{array}$ \\
\hline [27] & 123 & $46(57)$ & $73(90)$ & $19(23)$ & 40 & Rectal swabs & ICU patients \\
\hline [23] & 31 & $65(20)$ & $80(25)$ & $19(6)$ & 30 & Groin swabs & $\begin{array}{l}\text { General hospital, at risk } \\
\text { patients }\end{array}$ \\
\hline [31] & 224 & $67(151)$ & $69(155)$ & $12(26)$ & 17 & Groin swabs & ICU patients \\
\hline [39] & 71 & $76(54)$ & $76(54)$ & $20(14)$ & 26 & Rectal swabs & $\begin{array}{l}\text { General hospital, at risk } \\
\text { patients }\end{array}$ \\
\hline [19] & 22 & $73(16)$ & $71(12 / 17)$ & $30(5)$ & 31 & Perineal swabs & $\begin{array}{l}\text { Community-dwelling SCD } \\
\text { patients }\end{array}$ \\
\hline [36] & 78 & $77(60)$ & $73(57)$ & $27(21)$ & 35 & Perineal swabs & $\begin{array}{l}\text { ICU patients and other risk } \\
\text { factors }\end{array}$ \\
\hline [10] & 86 & $41(35)$ & $65(56)$ & $11(9)$ & 11 & Perianal swabs & Nursing home residents \\
\hline Totals & 2,195 & $45(978 / 2,195)$ & $58(1,306 / 2,268)$ & $18(287 / 1,614)$ & $35(287 / 833)$ & & \\
\hline
\end{tabular}

SCI, spinal cord injury; SCD, spinal cord dysfunction

${ }^{a}$ Totals are indicated when frequencies reported are based on different total numbers of cases

MRSA in the nose. Of all MRSA-colonized individuals detected in these studies more than 1 out of $6(18 \%)$ presented with intestinal carriage in the absence of nasal carriage. Such frequencies suggest that the intestines might be clinically relevant reservoirs of MRSA that should be taken into account during screening for such carriage during outbreak situations or when screening patients at risk.

\section{Intestinal or perineal carriage as a risk factor for dissemination and infections}

The perineum, as an area where $S$. aureus can colonize and multiply, was first recognized by Hare and Ridley [41], and heavy contamination from the perineum to the groin and upper parts of the thighs is often observed [42]. Both intestinal and perineal carriage have been implicated as important contributors to environmental dissemination of $S$. aureus. Patients with intestinal colonization of $S$. aureus may serve as an important source of transmission, since they often contaminate the adjacent environment. Masaki et al. [43] performed a prospective culture survey to investigate a possible relationship between $S$. aureus types colonizing the rectum and respiratory tract and $S$. aureus types isolated from the environment. They simultaneously detected in both patients and the environment several $S$. aureus types. This indicates a potential route of contamination of the hospital environment. It was also reported that 
patients with intestinal and nasal colonization of $S$. aureus had higher frequencies of incontinence or diarrhea than patients without $S$. aureus colonization. This may significantly contribute to the observed trend toward increased contamination of environmental surfaces [44, 45]. The latter studies also substantiated that patients who have diarrheal stools and heavy gastro-intestinal colonization with MRSA are associated with significantly greater environmental MRSA contamination than patients without MRSA in their stools.

Data from early studies suggested an association between intestinal colonization and the occurrence of infections. For example, a study on recurrent furunculosis showed that $56 \%$ of the patients sampled had positive perineal cultures [46]. This suggested intestinal $S$. aureus carriage to be an infection risk factor, although nasal carriage was not precisely assessed for those patients. Hospitalized patients who reported developing $S$. aureus lesions on the buttocks and lower half of the abdomen and back often had the causative strain isolated from the perineum as well [47]. It was found that intensive care and liver transplant unit patients with both nasal and intestinal colonization had significantly increased rates of S. aureus infection of $40 \%$ compared with an infection rate of $18 \%$ in patients with nasal carriage without intestinal carriage [48]. On the basis of these data it was concluded that rectal carriage represents a potential reservoir and simultaneous nasal and rectal carriage portended a greater risk of S. aureus infections than nasal carriage alone in ICU and liver transplant unit patients. The same authors also proposed that intestinal colonization could be associated with an increased frequency of colonization of skin sites, which was confirmed in later studies [44]. It was found that patients with nasal and intestinal colonization were significantly more likely than those with nasal colonization only to have positive skin cultures. This group performed a prospective study involving 71 patients. The patients enrolled were divided into three groups: those without nasal or intestinal colonization, those with nasal colonization only, and those with both nasal and intestinal colonization. The development of $S$. aureus infections was significantly different among the three groups. Only 1 out of 32 patients without nasal or intestinal colonization developed an $S$. aureus infection. $S$. aureus infections developed more often in patients with stool colonization (8 out of 26) than in patients with only nasal colonization ( 2 out of 13). However, due to the small number of infected patients the power of this study was too limited to reach statistical significance. Significant differences in staphylococcal infection between patients with $S$. aureus in the stools and patients with negative stool cultures for S. aureus were documented [49]. In an 8-month prospective study of inpatients known to have vancomycinresistant enterococci (VRE) colonization, none of the 14 patients with stool cultures negative for $S$. aureus developed an $S$. aureus infection in the hospital. In contrast, more than half of $S$. aureus-colonized patients had an $S$. aureus infection documented.

\section{Eradication of intestinal carriage}

Given its relatively high incidence, prevention of or therapy for intestinal carriage should be clinically beneficial. However, most studies are focused on the elimination of nasal rather than intestinal carriage. Nasal carriage eradication with mupirocin ointment has been studied frequently (recently reviewed by Van Rijen et al. [50]) and is generally considered to be highly effective, at least in the short term. However, reacquisition of carriage may occur from extranasal sites. Dupeyron et al. [51] monitored mupirocin treatment of 86 patients and found treatment failure in 22 . For this group, the stool carriage rate was significantly higher and stool carriage upon admission was independently associated with reacquisition of nasal carriage. Conflicting results regarding the effects of nasal carriage eradication on the prevalence of MSSA/MRSA infections have been reported. Some authors showed significantly decreased rates of nosocomial infections [52, 53], whereas others did not $[54,55]$.

Mupirocin treatment may only be marginally effective in the eradication of multi-site carriage and, therefore, therapies based upon combinations of nasal, skin, and intestinal carriage eradication methods have more recently been exploited. The use of oral rifampin, for treatment of intestinal carriage of $S$. aureus for various patient populations and healthy people was reviewed by Falagas et al. [56, 57]. Rifampin, however, showed limited success in MRSA elimination. More novel treatment modalities for intestinal MRSA elimination to control transmission or subsequent infections, e.g., using oral vancomycin, have been described merely in uncontrolled or observational studies. Oral vancomycin treatment results were reported that showed that the eradication of MRSA intestinal carriage by enteral vancomycin in subsets of adult ICU patients [5860] as well as in pediatric patients [61, 62] was effective, but had limited effect on the prevention of transmission. The results from prospective controlled studies of intestinal MRSA decolonization are urgently awaited.

Colonization of the intestinal tract by $S$. aureus may have another important clinical implication. The co-existence of S. aureus and VRE was reported in more than $50 \%$ of the American patients studied [49]. In this study, stool specimens were tested for VRE and $S$. aureus at enrollment (baseline) and weekly thereafter. Patients with at least three stool cultures were included in the study. Of the 37 patients who completed the study, all were colonized with VRE; $62 \%$ 
were colonized with $S$. aureus on at least one occasion, and $60 \%$ were colonized persistently. Patients with stool cultures positive for $S$. aureus were colonized with MRSA strains in $87 \%$ of all cases. Warren et al. [63] screened stools and rectal samples from 878 ICU patients for VRE and MRSA. Of 485 VRE-positive patients, 83 (17\%) also had intestinal carriage of MRSA. Furuno et al. [64] reported that out of 57 patients with both nasal MRSA carriage and intestinal VRE, 23 $(40 \%)$ also had intestinal carriage of MRSA. These studies suggest that the intestinal tract could provide an important reservoir for the emergence of vancomycin-resistant $S$. aureus (VRSA) isolates

The emergence of the rectal carriage of CA-MRSA has been documented in a study in which $S$. aureus was detected in 507 of 2,963 vaginal/rectal cultures from late pregnancy cases (17\%) [65]. Interestingly, $3 \%$ of the pregnant women had vaginal-rectal colonization of an epidemic CA-MRSA strain. A significant association between $S$. aureus colonization and Group B streptococcus (GBS) colonization was found. In a subsequent study this association was analyzed in more detail [66] and the significant association between MSSA and GBS was confirmed. Pregnant women with MSSA carriage were significantly more likely to have postpartum fever than those who were $S$. aureus-negative. Surprisingly, a significant negative association between CA-MRSA carriage and GBS carriage was observed. Apparently, when a certain bacterial species inhabits a given niche other species may not be able to colonize. In the case of the vaginal carriage of MRSA or MSSA such bacterial interference may lead to novel modes of intervention based on interference therapy of GBS once the microbial molecules involved have been identified.

\section{Potential role of $S$. aureus in intestinal disease}

How $S$. aureus causes intestinal infections is still ill-defined. The basic mechanisms are quite enigmatic and the etiological processes are just beginning to be identified. For instance, Froberg et al. [67] presented histo-pathological evidence for the existence of a specific $S$. aureus-induced pseudomembranous intestinal disease, distinct from that seen during $C$. difficile infection in an unusual case of simultaneous infection with $C$. difficile and MRSA. Whereas $C$. difficile induces colonic pseudomembranes, the MRSA infection induced loosely adherent pseudomembranes in the small bowel.

Intestinal carriage of $S$. aureus may impose a risk factor for intestinal infection. Antibiotic treatment can lead to the overgrowth of bacteria in the intestine and induce enteritis or AAD. The role of intestinal S. aureus as a causative agent for enteritis or AAD and as a risk factor for other infections gained renewed interest with the spreading of MRSA. MRSA has been suggested as a cause of AAD in hospitalized patients [68]. In this study $S$. aureus was the only identified pathogenic micro-organism to cause AAD in 47 patients and the presence of staphylococcal enterotoxin A was strongly associated with the development of diarrhea. A German study reported intestinal carriage of $S$. aureus, in the absence of $C$. difficile in $8 \%$ of patients with AAD [69]. Compelling evidence for the etiological role of MRSA in AAD was provided by excluding the involvement of $C$. difficile, numerous other bacterial pathogens and parasites, but also several enteric viruses in 11 patients with enterotoxin-producing MRSA intestinal carriage [70].

An extensive analysis of the prevalence of $C$. difficile and $S$. aureus in 2,727 stool samples of patients with diarrhea was performed. $C$. difficile grew from 148 specimens and 184 were positive for $C$. difficile toxin A/B analysis and altogether, a total of 252 stool samples were positively diagnosed with $C$. difficile. S. aureus was grown out of 198 fecal samples, of which 29 were identified as having MRSA [71]. In another study 10 MRSA-positive samples were detected out of 4,659 fecal samples [72]. Table 5 conclusively defines the interrelatedness between intestinal colonization by $S$. aureus and $C$. difficile.

\section{Intestinal $S$. aureus colonization and disease development in infants and young children}

In infants very high frequencies for intestinal $S$. aureus carriage were reported in early studies (reviewed by Williams [4], Table 6) and some of these suggested that acquisition of $S$. aureus occurred very early in life and probably as a consequence of nasal acquisition. Intestinal colonization in children was also studied more recently [73]. One hundred patients, below 16 years of age and attending the emergency department of a university hospital, who were analyzed for nasal and perineal carriage, included $20 \mathrm{~S}$. aureus-colonized patients, of whom $2(10 \%)$ had intestinal carriage in the absence of nasal carriage. Of this group, 17 patients (85\%) had nasal carriage. Others studied $S$. aureus carriage in a child care center [74]. Of

Table 5 Frequency of detection of $C$. difficile and $S$. aureus in antibiotic-associated diarrhea (AAD) patients

\begin{tabular}{lrlc}
\hline Reference & Total & $\begin{array}{l}\text { C. difficile, } \\
\text { percentage }(n)\end{array}$ & $\begin{array}{l}\text { S. aureus, } \\
\text { percentage }(n)\end{array}$ \\
\hline$[68]$ & 3,437 & $13(460)$ & $2(60)$ \\
{$[70]$} & 1,543 & $10(159)$ & $10(151)$ \\
{$[69]$} & 89 & $44(39)$ & $28(25)$ \\
{$[72]$} & 4,659 & $13(591)$ & $0.2(10)$ \\
{$[71]$} & 2,727 & $9(252)$ & $7(198)$ \\
\hline
\end{tabular}


Table 6 S. aureus intestinal carriage in infants

\begin{tabular}{|c|c|c|c|c|}
\hline References & Cases & Percentage & Method & Age \\
\hline [92] & $\begin{array}{l}83 \\
22 \\
32\end{array}$ & $\begin{array}{r}56 \\
100 \\
50\end{array}$ & Stools & $\begin{array}{l}1-10 \text { days } \\
2-6 \text { months } \\
6- \\
12 \text { months }\end{array}$ \\
\hline [76] & 62 & 61 & Stools & 2 years \\
\hline [73] & 100 & 19 & Perineal swabs & $\begin{array}{l}\text { Hospitalized } \\
\text { children up } \\
\text { to } 16 \text { years }\end{array}$ \\
\hline [78] & 49 & $\begin{array}{l}16 \\
57 \\
65 \\
65 \\
73 \\
73 \\
53\end{array}$ & Rectal/stools & $\begin{array}{l}3 \text { days } \\
1 \text { week } \\
2 \text { weeks } \\
4 \text { weeks } \\
8 \text { weeks } \\
6 \text { months } \\
1 \text { year }\end{array}$ \\
\hline [98] & 44 & $\begin{array}{l}59 \\
61 \\
50 \\
39 \\
32\end{array}$ & Stools & $\begin{array}{l}1 \text { week } \\
1 \text { month } \\
3 \text { months } \\
6 \text { months } \\
12 \text { months }\end{array}$ \\
\hline [77] & 50 & $\begin{array}{l}20 \\
40 \\
52 \\
60 \\
64\end{array}$ & Rectal/stools & $\begin{array}{l}3 \text { days } \\
1 \text { week } \\
2 \text { weeks } \\
4 \text { weeks } \\
8 \text { weeks }\end{array}$ \\
\hline [79] & 53 & $\begin{array}{l}62 \\
70\end{array}$ & Rectal swabs & $\begin{array}{l}2 \text { weeks } \\
4 \text { weeks }\end{array}$ \\
\hline [80] & 324 & $\begin{array}{l}13 \\
39 \\
52 \\
63 \\
72 \\
79\end{array}$ & Rectal swabs & $\begin{array}{l}3 \text { days } \\
7 \text { days } \\
14 \text { days } \\
28 \text { days } \\
2 \text { months } \\
6 \text { months }\end{array}$ \\
\hline
\end{tabular}

128 children who had swabs taken from nose, perineum, and throat, $8(24 \%)$ had perineal carriage. Nasal and throat carriage frequency were higher with $15(46 \%)$ and 22 (67\%) respectively. An African study investigated the incidence of $S$. aureus in children aged 5 years and below suffering from sporadic diarrhea in Nigeria [75]. Out of 1,761 diarrheic fecal specimens collected, only $72(4 \%)$ were positive for $S$. aureus.

Also, in more recent Swedish studies [76-79], high frequencies of intestinal $S$. aureus carriage during the first year of life were reported, and co-colonization of intestine and anterior nares with the same $S$. aureus strains, which were also found on the parents, suggested mother- to-child transmission. These studies were performed to test the hypothesis that development of allergic disease among children may be associated with differences in intestinal colonization patterns of $S$. aureus. Two-year-old allergic children from both Sweden and Estonia were reported to have significantly higher counts of $S$. aureus in the intestines than non-allergic children [76]. In a prospective follow-up study, significantly increased $S$. aureus intestinal prevalence at 6 months of age was found in a group of allergic children compared with the non-allergic group. An interesting correlation between intestinal colonization with S. aureus at 2 and 4 weeks of age and the development of food allergy was observed by Lundell et al. [79]. They also found a correlation between perinatal intestinal $S$. aureus colonization and expression levels of the soluble immune modulator CD14, but not the levels of CD83, and concluded that colonization with $S$. aureus might modulate the development of the neonatal immune system. This indicates an interrelatedness between factors involved in the host's immune response, early colonization, and development of allergic disease. Adlerberth et al. [80] studied the hypothesis that infantile intestinal colonization patterns may influence sensitization to food allergens and atopic eczema. They analyzed a birth cohort of more than 300 infants from three European countries with regard to relations between intestinal colonization patterns during the first year and the development of atopic eczema and sensitization at 18 months of age. They reported a nearly significant association $(p=0.06)$ between early intestinal colonization with $S$. aureus and increased risk of atopic eczema. Kalliomaki et al. [81] recently observed that higher numbers of fecal $S$. aureus carriage at 6 and 12 months of age were associated with obesity in children.

Bisgaard et al. [82], who studied a Danish birth cohort of 411 infants, did not observe any correlation between neonatal airway colonization with $S$. aureus at 1 month of age and the development of childhood asthma. In contrast, for colonization with the classical otitis media bacteria $S$. pneumonia, $M$. catarrhalis and $H$. influenzae a significant association with increased persistent or acute wheezing and hospitalization for wheezing was observed. This seems to indicate a lack of influence of $S$. aureus colonization. However, since these studies were performed in a high-risk cohort, an alternative plausible interpretation of these data is that $S$. aureus to a greater extent than the other bacteria mentioned may modulate the neonatal immune system, and that the lower rates of wheezing associated with $S$. aureus colonization may actually reflect relative protection. This may be in line with observed differences in immune induction between gram-positive and gram-negative bacteria and the risk of childhood asthma [83]. The potential involvement of $S$. aureus enterotoxins (SE) in allergic diseases in early childhood by following 510 children from birth to 5 years of age was studied by Semic-Jusufagic et al. [84]. SE-mix-specific IgE, (SE-A, SE-C, and TSST-1) were measured to determine SE sensitization and correlated with atopic disease. Atopic children were nearly 4 times more SE-mix-sensitive than non-atopic children. Children with eczema were significantly more frequently SE-mix sensi- 
tized than children without and the SE-mix sensitization rate increased significantly with increasing eczema severity. SE-mix sensitization was also significantly associated with current wheezing. Furthermore, SE-mix-sensitized children with wheezing had significantly higher airway reactivity than wheezing children who were not sensitized to SE-mix, which suggests that enterotoxins from $S$. aureus might be potential modifiers of childhood wheezing and eczema.

\section{Intestinal MRSA in infants and young children at risk}

Paired analysis of nasal and intestinal colonization during separate outbreaks of MRSA in children and newborns has been reported in a limited number of studies. After identification of a single case of MRSA infection, 128 children from a child care center were assessed for MSSA/MRSA carriage by perianal, nasal, and throat swabs [74]. This analysis identified an additional MRSA carrier only from the perianal swab, whereas the two other sites were negative. Singh et al. [85] found that during an MRSA outbreak at the neonatal intensive care unit of two hospitals, out of 373 infants analyzed, 24 were positive for MRSA. Of these, 7 (29\%) had positive rectal cultures, of whom $1(0.4 \%)$ was negative for nasal carriage. In 17 infants (71\%) only the nasal culture was positive. Investigations during two MRSA outbreaks (one with a HA-MRSA and one with a CA-MRSA strain) were performed using paired nasal and intestinal screening [86]. Altogether, 1,792 newborns were screened and 50 were MRSA-positive. In the first hospital, out of 25 infants positively screened, $17(71 \%)$ had nasal carriage and 5 $(21 \%)$ had carriage in the rectum, all of whom also had nasal carriage. In the second hospital, 18 out of 25 positively screened $(72 \%)$ had nasal carriage and 15 out of 25 infants $(60 \%)$ had rectal carriage, of whom $3(12 \%)$ did not have nasal carriage. The use of surveillance cultures of throat and rectal swabs in a pediatric intensive care unit is important [62]. Among 1,241 patients analyzed there were 29 MRSA carriers, of whom $14(48 \%)$ had rectal carriage. Gustafsson et al. [87] described a study on MRSA carriage in 23 children adopted by Swedish families. Multiple swabs were taken from the perineum, nose, and other sites. MRSA was detected in 13 of the children. The perineum culture was positive at least once in 9 children (69\%) and the nose was positive in 9 children (69\%). Interestingly, 4 perineal MRSA carriers (31\%) did not have nasal carriage.

Altogether, from these studies it can be deduced that of all the newborns or young children in whom MRSA was detected, $74 \%$ had nasal or throat carriage and $44 \%$ had intestinal carriage (Table 7). Moreover, 10\% had intestinal carriage without nasal or throat carriage, which indicates that, in addition to nasal or throat carriage, the perineum or intestine also constitutes a colonization site with potential infection risk in newborns and young children.

\section{Concluding remarks}

Intestinal carriage of $S$. aureus occurs in a significant fraction of both healthy and diseased human individuals. For healthy adults and hospitalized adults at risk the incidence figure is $20 \%$. For MRSA the average fraction of intestinal carriers amongst adult patients at risk is $9 \%$. In young children the colonization of the intestines with $S$. aureus occurs at a very high frequency within the first 6 months of life, after which the frequency drops. For newborns and young children intestinal colonization with MRSA was detected in $1-2 \%$ of patients screened. This shows that the clinical impact of this phenomenon may be significant, which was corroborated in a number of studies that associated carriage and intestinal infection. Both MSSA and MRSA seem to successfully colonize the human intestines. This further emphasizes that care has to be taken: not only MSSA infections but also MRSA infection can result from intestinal carriage. Since MSSA and MRSA nasal carriage has been implicated to be a highly important risk factor for infections, the same will probably apply to intestinal carriage. Therefore, prospective controlled studies of intestinal carriage as a predictor of clinical infection need to be performed to determine the significance of this site of colonization. Prolonged intestinal carriage, also among personnel, can be an important factor

Table 7 Intestinal MRSA carriage in young children at risk

\begin{tabular}{|c|c|c|c|c|c|}
\hline Reference & Total patients screened & Total positive carriers & Rectal MRSA & Nasal MRSA & Rectal without nasal \\
\hline [74] & 128 & 1 & 1 & 0 & 1 \\
\hline$[85]$ & 373 & 24 & 7 & 17 & 1 \\
\hline$[86]$ & 1,792 & 50 & 20 & 35 & 3 \\
\hline$[62]$ & 1,241 & 29 & 14 & $26^{\mathrm{a}}$ & $3^{\mathrm{a}}$ \\
\hline [87] & 23 & 13 & 9 & 9 & 4 \\
\hline Totals & 3,557 & 117 & 51 & 87 & 12 \\
\hline Percentage of total positive carriers & & & $44 \%$ & $74 \%$ & $10 \%$ \\
\hline
\end{tabular}

${ }^{\mathrm{a}}$ Throat swab analyzed instead of nasal swab 
in the persistence of MRSA outbreaks in hospitals and can be a source of environmental contamination. The development of rapid molecular detection methods for MRSA carriage facilitates prophylaxis [88]. Nasally applied mupirocin very effectively eliminates nasal carriage and results in significant reductions in $S$. aureus infection rates. Mupirocin seems less effective for the elimination of intestinal carriage or other extra-nasal sites. Therefore, application of combined strategies, involving mupirocin in combination with oral antibiotics or other selective intestinal decontamination regiments, such as novel therapies based on polyclonal antibodies [89], may be more effective in cases of proven nasal and intestinal carriage. Because of the significant frequencies of intestinal carriage reported in a wide variety of patient groups and in healthy people it is recommended, in addition to nasal screening, to also include intestinal or perianal screening during surveillance.

Little is known on the age-related kinetics of intestinal carriage, but $S$. aureus seems to colonize the intestine of healthy newborns from very early in life onwards, and can be involved in the development of neonatal infectious disease. Later in life, intestinal carriage frequencies seem to drop. In concordance with nasal carriage, non-, intermittent and persistent intestinal carriage need to be defined in more detail. It is, therefore, of importance to determine whether specific variants of $S$. aureus are more proficient colonizers than others and which adhesion and virulence factors play a role in the transition from intestinal colonization to infection. Even more importantly, little is known on the environmental, bacteriological and physiological determinants of intestinal carriage. Preliminary data identify intestinal carriage as an infection risk factor and results from cohort studies suggest that there is interrelatedness among early intestinal colonization of $S$. aureus, the host's immune system, and the development of disease later in life. Additional research, however, will be needed to fully appreciate the importance of intestinal $S$. aureus colonization in association with infection.

Open Access This article is distributed under the terms of the Creative Commons Attribution Noncommercial License which permits any noncommercial use, distribution, and reproduction in any medium, provided the original author(s) and source are credited.

\section{References}

1. Kluytmans J, van Belkum A, Verbrugh H (1997) Nasal carriage of Staphylococcus aureus: epidemiology, underlying mechanisms, and associated risks. Clin Microbiol Rev 10:505-520

2. Weinstein HJ (1959) The relation between the nasal-staphylococcalcarrier state and the incidence of postoperative complications. N Engl J Med 260:1303-1308
3. Wertheim HF, Melles DC, Vos MC, van Leeuwen W, van Belkum A et al (2005) The role of nasal carriage in Staphylococcus aureus infections. Lancet Infect Dis 5:751-762

4. Williams RE (1963) Healthy carriage of Staphylococcus aureus: its prevalence and importance. Bacteriol Rev 27:56-71

5. Larson HE, Price AB, Honour P, Borriello SP (1978) Clostridium difficile and the aetiology of pseudomembranous colitis. Lancet 311:1063-1066

6. Metan G, Zarakolu P, Unal S (2005) Rapid detection of antibacterial resistance in emerging Gram-positive cocci. J Hosp Infect 61:93-99

7. Crossley K, Solliday J (1980) Comparison of rectal swabs and stool cultures for the detection of gastrointestinal carriage of Staphylococcus aureus. J Clin Microbiol 11:433-434

8. Lee DC, Barlas D, Ryan JG, Ward MF, Sama AE et al (2002) Methicillin-resistant Staphylococcus aureus and vancomycinresistant enterococci: prevalence and predictors of colonization in patients presenting to the emergency department from nursing homes. J Am Geriatr Soc 50:1463-1465

9. Meurman O, Routamaa M, Peltonen R (2005) Screening for methicillin-resistant Staphylococcus aureus: which anatomical sites to culture. J Hosp Infect 61:351-353

10. Mody L, Kauffman CA, Donabedian S, Zervos M, Bradley SF (2008) Epidemiology of Staphylococcus aureus colonization in nursing home residents. Clin Infect Dis 46:1368-1373

11. Drews SJ, Willey BM, Kreiswirth N, Wang M, Ianes T et al (2006) Verification of the IDI-MRSA assay for detecting methicillinresistant Staphylococcus aureus in diverse specimen types in a core clinical laboratory setting. J Clin Microbiol 44:3794-3796

12. Buehlmann M, Frei R, Fenner L, Dangel M, Fluckiger U et al (2008) Highly effective regimen for decolonization of methicillinresistant Staphylococcus aureus carriers. Infect Control Hosp Epidemiol 29:510-516

13. Rimland D, Roberson B (1986) Gastrointestinal carriage of methicillin-resistant Staphylococcus aureus. J Clin Microbiol 24:137-138

14. Matthias JQ, Shooter RA, Williams RE (1957) Staphylococcus aureus in the faeces of hospital patients. Lancet 272:1172-1173

15. Boe J, Solberg CO, Vogelsang TM, Wormnes A (1964) Perineal carriers of staphylococci. BMJ 2:280-281

16. Ridley M (1959) Perineal carriage of Staphylococcus aureus. BMJ $1: 270-273$

17. Dancer SJ, Noble WC (1991) Nasal, axillary, and perineal carriage of Staphylococcus aureus among women: identification of strains producing epidermolytic toxin. J Clin Pathol 44:681-684

18. Lee YL, Cesario T, Gupta G, Flionis L, Tran C et al (1997) Surveillance of colonization and infection with Staphylococcus aureus susceptible or resistant to methicillin in a community skilled-nursing facility. Am J Infect Control 25:312-321

19. Roghmann MC, Gorman PH, Wallin MT, Kreisel K, Shurland S et al (2007) Staphylococcus aureus colonization in communitydwelling people with spinal cord dysfunction. Arch Phys Med Rehabil 88:979-983

20. Borer A, Gilad J, Yagupsky P, Peled N, Porat N et al (2002) Community-acquired methicillin-resistant Staphylococcus aureus in institutionalized adults with developmental disabilities. Emerg Infect Dis 8:966-970

21. Van Hal SJ, Stark D, Lockwood B, Marriott D, Harkness J (2007) Methicillin-resistant Staphylococcus aureus (MRSA) detection: comparison of two molecular methods (IDI-MRSA PCR assay and GenoType MRSA Direct PCR assay) with three selective MRSA agars (MRSA ID, MRSASelect, and CHROMagar MRSA) for use with infection-control swabs. J Clin Microbiol 45:2486-2490

22. Aeilts GD, Sapico FL, Canawati HN, Malik GM, Montgomerie JZ (1982) Methicillin-resistant Staphylococcus aureus colonization and infection in a rehabilitation facility. J Clin Microbiol 16:218-223 
23. Bishop EJ, Grabsch EA, Ballard SA, Mayall B, Xie S et al (2006) Concurrent analysis of nose and groin swab specimens by the IDIMRSA PCR assay is comparable to analysis by individualspecimen PCR and routine culture assays for detection of colonization by methicillin-resistant Staphylococcus aureus. J Clin Microbiol 44:2904-2908

24. Cavalcanti SM, Franca ER, Cabral C, Vilela MA, Montenegro F et al (2005) Prevalence of Staphylococcus aureus introduced into intensive care units of a University Hospital. Braz J Infect Dis 9:56-63

25. Coello R, Jimenez J, Garcia M, Arroyo P, Minguez D et al (1994) Prospective study of infection, colonization and carriage of methicillin-resistant Staphylococcus aureus in an outbreak affecting 990 patients. Eur J Clin Microbiol Infect Dis 13:74-81

26. Darouiche R, Wright C, Hamill R, Koza M, Lewis D et al (1991) Eradication of colonization by methicillin-resistant Staphylococcus aureus by using oral minocycline-rifampin and topical mupirocin. Antimicrob Agents Chemother 35:1612-1615

27. Eveillard M, de Lassence A, Lancien E, Barnaud G, Ricard JD et al (2006) Evaluation of a strategy of screening multiple anatomical sites for methicillin-resistant Staphylococcus aureus at admission to a teaching hospital. Infect Control Hosp Epidemiol 27:181-184

28. Gnanalingham KK, Elsaghier A, Kibbler C, Shieff C (2003) The impact of methicillin-resistant Staphylococcus aureus in a neurosurgical unit: a growing problem. J Neurosurg 98:8-13

29. Kampf G, Kramer A (2004) Eradication of methicillin-resistant Staphylococcus aureus with an antiseptic soap and nasal mupirocin among colonized patients - an open uncontrolled clinical trial. Ann Clin Microbiol Antimicrob 3:9

30. Klotz M, Zimmermann S, Opper S, Heeg K, Mutters R (2005) Possible risk for re-colonization with methicillin-resistant Staphylococcus aureus (MRSA) by faecal transmission. Int J Hyg Environ Health 208:401-405

31. Lim MS, Marshall CL, Spelman D (2006) Carriage of multiple subtypes of methicillin-resistant Staphylococcus aureus by intensive care unit patients. Infect Control Hosp Epidemiol 27:1063-1067

32. Maeder K, Ginunas VJ, Montgomerie JZ, Canawati HN (1993) Methicillin-resistant Staphylococcus aureus (MRSA) colonization in patients with spinal cord injury. Paraplegia 31:639-644

33. Manian FA, Senkel D, Zack J, Meyer L (2002) Routine screening for methicillin-resistant Staphylococcus aureus among patients newly admitted to an acute rehabilitation unit. Infect Control Hosp Epidemiol 23:516-519

34. Mylotte JM, Kahler L, Graham R, Young L, Goodnough S (2000) Prospective surveillance for antibiotic-resistant organisms in patients with spinal cord injury admitted to an acute rehabilitation unit. Am J Infect Control 28:291-297

35. Papia G, Louie M, Tralla A, Johnson C, Collins V et al (1999) Screening high-risk patients for methicillin-resistant Staphylococcus aureus on admission to the hospital: is it cost effective. Infect Control Hosp Epidemiol 20:473-477

36. Reyes RC, Stoakes L, Milburn S, Lennox G, Daniel J et al (2008) Evaluation of a new chromogenic medium for the detection of methicillin-resistant Staphylococcus aureus carriage on nasal and perianal specimens. Diagn Microbiol Infect Dis 60:225-227

37. Roberts S, Young H, Faulkner S, Bilkey M, Eyres S et al (2002) Value of broth cultures in detecting methicillin-resistant Staphylococcus aureus. NZ Med J 115:U191

38. Trick WE, Weinstein RA, DeMarais PL, Kuehnert MJ, Tomaska W et al (2001) Colonization of skilled-care facility residents with antimicrobial-resistant pathogens. J Am Geriatr Soc 49:270-276

39. Zhang SX, Drews SJ, Tomassi J, Katz KC (2007) Comparison of two versions of the IDI-MRSA assay using charcoal swabs for prospective nasal and nonnasal surveillance samples. J Clin Microbiol 45:2278-2280
40. Simor AE, Ofner-Agostini M, Paton S, McGeer A, Loeb M et al (2005) Clinical and epidemiologic features of methicillin-resistant Staphylococcus aureus in elderly hospitalized patients. Infect Control Hosp Epidemiol 26:838-841

41. Hare R, Ridley M (1958) Further studies on the transmission of Staphylococcus aureus. BMJ 1:69-73

42. Solberg CO (2000) Spread of Staphylococcus aureus in hospitals: causes and prevention. Scand J Infect Dis 32:587-595

43. Masaki H, Asoh N, Watanabe H, Tao M, Watanabe K et al (2003) Possible relationship between Staphylococcus aureus colonizing the respiratory tract and rectum and $S$. aureus isolated in a geriatric hospital environment. Intern Med 42:281-282

44. Bhalla A, Aron DC, Donskey CJ (2007) Staphylococcus aureus intestinal colonization is associated with increased frequency of $\mathrm{S}$. aureus on skin of hospitalized patients. BMC Infect Dis 7:105

45. Boyce JM, Havill NL, Otter JA, Adams NM (2007) Widespread environmental contamination associated with patients with diarrhea and methicillin-resistant Staphylococcus aureus colonization of the gastrointestinal tract. Infect Control Hosp Epidemiol 28:1142-1147

46. Tulloch LG, Alder VG, Gillespie WA (1960) Treatment of chronic furunculosis. BMJ 2:354-356

47. Solberg CO (1965) A study of carriers of Staphylococcus aureus with special regard to quantitative bacterial estimations. Acta Med Scand Suppl 436:1-96

48. Squier C, Rihs JD, Risa KJ, Sagnimeni A, Wagener MM et al (2002) Staphylococcus aureus rectal carriage and its association with infections in patients in a surgical intensive care unit and a liver transplant unit. Infect Control Hosp Epidemiol 23:495-501

49. Ray AJ, Pultz NJ, Bhalla A, Aron DC, Donskey CJ (2003) Coexistence of vancomycin-resistant enterococci and Staphylococcus aureus in the intestinal tracts of hospitalized patients. Clin Infect Dis $37: 875-881$

50. Van Rijen MM, Bonten M, Wenzel RP, Kluytmans JA (2008) Intranasal mupirocin for reduction of Staphylococcus aureus infections in surgical patients with nasal carriage: a systematic review. J Antimicrob Chemother 61:254-261

51. Dupeyron C, Campillo B, Bordes M, Faubert E, Richardet JP et al (2002) A clinical trial of mupirocin in the eradication of methicillin-resistant Staphylococcus aureus nasal carriage in a digestive disease unit. J Hosp Infect 52:281-287

52. Dupeyron C, Campillo B, Richardet JP, Soussy CJ (2006) Longterm efficacy of mupirocin in the prevention of infections with meticillin-resistant Staphylococcus aureus in a gastroenterology unit. J Hosp Infect 63:385-392

53. Perl TM, Cullen JJ, Wenzel RP, Zimmerman MB, Pfaller MA et al (2002) Intranasal mupirocin to prevent postoperative Staphylococcus aureus infections. N Engl J Med 346:1871-1877

54. Harbarth S, Dharan S, Liassine N, Herrault P, Auckenthaler R et al (1999) Randomized, placebo-controlled, double-blind trial to evaluate the efficacy of mupirocin for eradicating carriage of methicillin-resistant Staphylococcus aureus. Antimicrob Agents Chemother 43:1412-1416

55. Wertheim HF, Verveer J, Boelens HA, van Belkum A, Verbrugh HA et al (2005) Effect of mupirocin treatment on nasal, pharyngeal, and perineal carriage of Staphylococcufs aureus in healthy adults. Antimicrob Agents Chemother 49:1465-1467

56. Falagas ME, Bliziotis IA, Fragoulis KN (2007) Oral rifampin for eradication of Staphylococcus aureus carriage from healthy and sick populations: a systematic review of the evidence from comparative trials. Am J Infect Control 35:106-114

57. Falagas ME, Fragoulis KN, Bliziotis IA (2006) Oral rifampin for prevention of Staphylococcus aureus carriage-related infections in patients with renal failure - a meta-analysis of randomized controlled trials. Nephrol Dial Transplant 21:2536-2542

58. Cerda E, Abella A, de la Cal MA, Lorente JA, Garcia-Hierro P et al (2007) Enteral vancomycin controls methicillin-resistant 
Staphylococcus aureus endemicity in an intensive care burn unit: a 9-year prospective study. Ann Surg 245:397-407

59. De la Cal MA, Cerda E, van Saene HK, Garcia-Hierro P, Negro E et al (2004) Effectiveness and safety of enteral vancomycin to control endemicity of methicillin-resistant Staphylococcus aureus in a medical/surgical intensive care unit. J Hosp Infect 56:175-183

60. Silvestri L, van Saene HK, Milanese M, Fontana F, Gregori D et al (2004) Prevention of MRSA pneumonia by oral vancomycin decontamination: a randomised trial. Eur Respir J 23:921-926

61. Solis A, Brown D, Hughes J, Van Saene HK, Heaf DP (2003) Methicillin-resistant Staphylococcus aureus in children with cystic fibrosis: an eradication protocol. Pediatr Pulmonol 36:189-195

62. Thorburn K, Taylor N, Saladi SM, van Saene HK (2006) Use of surveillance cultures and enteral vancomycin to control methicillinresistant Staphylococcus aureus in a paediatric intensive care unit. Clin Microbiol Infect 12:35-42

63. Warren DK, Liao RS, Merz LR, Eveland M, Dunne WM Jr (2004) Detection of methicillin-resistant Staphylococcus aureus directly from nasal swab specimens by a real-time PCR assay. J Clin Microbiol 42:5578-5581

64. Furuno JP, Perencevich EN, Johnson JA, Wright MO, McGregor JC et al (2005) Methicillin-resistant Staphylococcus aureus and vancomycin-resistant Enterococci co-colonization. Emerg Infect Dis 11:1539-1544

65. Chen KT, Huard RC, Della-Latta P, Saiman L (2006) Prevalence of methicillin-sensitive and methicillin-resistant Staphylococcus aureus in pregnant women. Obstet Gynecol 108:482-487

66. Chen KT, Campbell H, Borrell LN, Huard RC, Saiman L et al (2007) Predictors and outcomes for pregnant women with vaginalrectal carriage of community-associated methicillin-resistant Staphylococcus aureus. Am J Perinatol 24:235-240

67. Froberg MK, Palavecino E, Dykoski R, Gerding DN, Peterson LR et al (2004) Staphylococcus aureus and Clostridium difficile cause distinct pseudomembranous intestinal diseases. Clin Infect Dis 39:747-750

68. Gravet A, Rondeau M, Harf-Monteil C, Grunenberger F, Monteil H et al (1999) Predominant Staphylococcus aureus isolated from antibiotic-associated diarrhea is clinically relevant and produces enterotoxin A and the bicomponent toxin LukE-lukD. J Clin Microbiol 37:4012-4019

69. Ackermann G, Thomalla S, Ackermann F, Schaumann R, Rodloff AC et al (2005) Prevalence and characteristics of bacteria and host factors in an outbreak situation of antibiotic-associated diarrhoea. J Med Microbiol 54:149-153

70. Boyce JM, Havill NL, Maria B (2005) Frequency and possible infection control implications of gastrointestinal colonization with methicillin-resistant Staphylococcus aureus. J Clin Microbiol 43:5992-5995

71. Flemming K, Ackermann G (2007) Prevalence of enterotoxin producing Staphylococcus aureus in stools of patients with nosocomial diarrhea. Infection 35:356-358

72. Asha NJ, Tompkins D, Wilcox MH (2006) Comparative analysis of prevalence, risk factors, and molecular epidemiology of antibioticassociated diarrhea due to Clostridium difficile, Clostridium perfringens, and Staphylococcus aureus. J Clin Microbiol 44:2785-2791

73. Suggs AH, Maranan MC, Boyle-Vavra S, Daum RS (1999) Methicillin-resistant and borderline methicillin-resistant asymptomatic Staphylococcus aureus colonization in children without identifiable risk factors. Pediatr Infect Dis J 18:410-414

74. Shahin R, Johnson IL, Jamieson F, McGeer A, Tolkin J et al (1999) Methicillin-resistant Staphylococcus aureus carriage in a child care center following a case of disease. Toronto Child Care Center Study Group. Arch Pediatr Adolesc Med 153:864-868
75. Efuntoye MO, Adetosoye AI (2003) Enterotoxigenicity and drug sensitivity of staphylococci from children aged five years and below with sporadic diarrhoea. East Afr Med J 80:656-659

76. Bjorksten B, Naaber P, Sepp E, Mikelsaar M (1999) The intestinal microflora in allergic Estonian and Swedish 2-year-old children. Clin Exp Allergy 29:342-346

77. Lindberg E, Adlerberth I, Hesselmar B, Saalman R, Strannegard IL et al (2004) High rate of transfer of Staphylococcus aureus from parental skin to infant gut flora. J Clin Microbiol 42:530-534

78. Lindberg E, Nowrouzian F, Adlerberth I, Wold AE (2000) Long-time persistence of superantigen-producing Staphylococcus aureus strains in the intestinal microflora of healthy infants. Pediatr Res 48:741-747

79. Lundell AC, Adlerberth I, Lindberg E, Karlsson H, Ekberg S et al (2007) Increased levels of circulating soluble CD14 but not CD83 in infants are associated with early intestinal colonization with Staphylococcus aureus. Clin Exp Allergy 37:62-71

80. Adlerberth I, Strachan DP, Matricardi PM, Ahrne S, Orfei L et al (2007) Gut microbiota and development of atopic eczema in 3 European birth cohorts. J Allergy Clin Immunol 120:343-350

81. Kalliomaki M, Collado MC, Salminen S, Isolauri E (2008) Early differences in fecal microbiota composition in children may predict overweight. Am J Clin Nutr 87:534-538

82. Bisgaard H, Hermansen MN, Buchvald F, Loland L, Halkjaer LB et al (2007) Childhood asthma after bacterial colonization of the airway in neonates. N Engl J Med 357:1487-1495

83. Michelow IC, Fracchia MS, Kinane TB (2008) Asthma and neonatal airway colonization. N Engl J Med 358:423-425; author reply 424-425

84. Semic-Jusufagic A, Bachert C, Gevaert P, Holtappels G, Lowe L et al (2007) Staphylococcus aureus sensitization and allergic disease in early childhood: population-based birth cohort study. J Allergy Clin Immunol 119:930-936

85. Singh K, Gavin PJ, Vescio T, Thomson RB Jr, Deddish RB et al (2003) Microbiologic surveillance using nasal cultures alone is sufficient for detection of methicillin-resistant Staphylococcus aureus isolates in neonates. J Clin Microbiol 41:2755-2757

86. Rosenthal A, White D, Churilla S, Brodie S, Katz KC (2006) Optimal surveillance culture sites for detection of methicillin-resistant Staphylococcus aureus in newborns. J Clin Microbiol 44:4234-4236

87. Gustafsson EB, Ringberg H, Johansson PJ (2007) MRSA in children from foreign countries adopted to Swedish families. Acta Paediatr 96:105-108

88. Carroll KC (2008) Rapid diagnostics for methicillin-resistant Staphylococcus aureus: current status. Mol Diagn Ther 12:15-24

89. Numan SC, Veldkamp P, Kuijper EJ, van den Berg RJ, van Dissel JT (2007) Clostridium difficile-associated diarrhoea: bovine antiClostridium difficile whey protein to help aid the prevention of relapses. Gut 56:888-889

90. Singh N, Squier C, Wannstedt C, Keyes L, Wagener MM et al (2006) Impact of an aggressive infection control strategy on endemic Staphylococcus aureus infection in liver transplant recipients. Infect Control Hosp Epidemiol 27:122-126

91. Grmek-Kosnik I, Ihan A, Dermota U, Rems M, Kosnik M et al (2005) Evaluation of separate vs pooled swab cultures, different media, broth enrichment and anatomical sites of screening for the detection of methicillin-resistant Staphylococcus aureus from clinical specimens. J Hosp Infect 61:155-161

92. Buttiaux R, Pierret J (1949) Les staphylocoques pathogens dans les selles des nourissons normaux. Ann Inst Pasteur (Paris) 76:480-482

93. Brodie J, Sommerville T, Wilson SGF (1956) Coagulase positive staphylococci. A seral survey during the first six months of nursing training. BMJ 1:667-669

94. Grun L (1958) Studies on intestinal staphylococci. Arch Hyg Bakteriol 142:3-7 
95. Greendyke RM, Constantine HP, Magruder GB, Dean DC, Gardner JH et al (1958) Staphylococci on a medical ward, with special reference to fecal carriers. Am J Clin Pathol 30:318-322

96. Hofstad T, Wormnes A (1961) The effect of broad spectrum antibiotics on the faecal staphylococcal and monilial flora in man. Acta Pathol Microbiol Scand 51:275-279
97. Polakoff S, Richards ID, Parker MT, Lidwell OM (1967) Nasal and skin carriage of Staphylococcus aureus by patients undergoing surgical operation. J Hyg (Lond) 65:559-566

98. Bjorksten B, Sepp E, Julge K, Voor T, Mikelsaar M (2001) Allergy development and the intestinal microflora during the first year of life. J Allergy Clin Immunol 108:516-520 